\title{
CORRECTION
}

\section{Safety considerations \\ with chloroquine, hydroxychloroquine and azithromycin in the management of SARS-CoV-2 infection}

CMAJ has updated an article published in the Apr. 27, 2020, issue. ${ }^{1}$

In the section "Hematologic toxicities," in order to better reflect the findings of the study cited, the second and third sentences have been changed from

Primaquine is well known to cause this, but chloroquine and hydroxychloroquine are much less likely to do so. In a chart review of 275 rheumatology patients with established G6PD deficiency, no episodes of hydroxychloroquinerelated hemolysis were identified over more than 700 months of treatment. ${ }^{34}$

to

Primaquine is well known to cause this, but chloroquine and hydroxychloroquine are less likely to do so. In a chart review of 275 rheumatology patients of whom 11 were documented to have G6PD deficiency, no episodes of hydroxychloroquine-related hemolysis were identified over more than 700 months of treatment. ${ }^{34}$

The following resource, which was omitted from the earlier version, has been added to Box 2: The University of Liverpool COVID-19 Drug Interactions website (www.covid19-druginteractions.org/).

CMAJ apologizes for any inconvenience to the reader.

Cite as: CMAJ 2020 May 25;192:E590. doi: $10.1503 / \mathrm{cmaj} .200978$

\section{Reference}

1. Juurlink D. Safety considerations with chloroquine, hydroxychloroquine and azithromycin in the management of SARS-CoV-2 infection. CMAJ 2020;192:E450-3. 